\title{
Detection and Comparison of Bioactive Compounds in Different Extracts of Two Hazelnut Skin Varieties, Tonda Gentile Romana and Tonda Di Giffoni, Using a Metabolomics Approach
}

\author{
Veronica Lelli, Romina Molinari (D), Nicolò Merendino (D) and Anna Maria Timperio *(D)
}

check for

updates

Citation: Lelli, V.; Molinari, R.; Merendino, N.; Timperio, A.M. Detection and Comparison of Bioactive Compounds in Different Extracts of Two Hazelnut Skin Varieties, Tonda Gentile Romana and Tonda Di Giffoni, Using a Metabolomics Approach. Metabolites 2021, 11, 296. https://doi.org/ 10.3390/metabo11050296

Academic Editor: Jose M. Lorenzo

Received: 8 April 2021

Accepted: 2 May 2021

Published: 5 May 2021

Publisher's Note: MDPI stays neutral with regard to jurisdictional claims in published maps and institutional affiliations.

Copyright: (c) 2021 by the authors. Licensee MDPI, Basel, Switzerland. This article is an open access article distributed under the terms and conditions of the Creative Commons Attribution (CC BY) license (https:/ / creativecommons.org/licenses/by/ $4.0 /)$.
Department of Ecological and Biological Sciences, University of Tuscia, 01110 Viterbo, Italy; v.lelli@unitus.it (V.L.); molinari@unitus.it (R.M.); merendin@unitus.it (N.M.)

* Correspondence: timperio@unitus.it

\begin{abstract}
Agro-wastes are one of the major sources for nutritional and therapeutic benefits along with other beneficial properties. Dark brown pellicular pericarp (skin or testa), covering the hazelnut seed, is removed before consumption after the roasting of a kernel. Defatted skins of both hazelnut varieties, Tonda Gentile Romana and Tonda di Giffoni, were profiled by a metabolomics-based approach and this was used to discriminate between these two different hazelnut cultivars. In particular, an untargeted metabolomic extract from hazelnut by-products was investigated by UHPLC-Mass spectrometry followed by multivariate statistics analysis, and significant qualitative and quantitative metabolic differences were observed between them. Samples were also assessed for their total phenolic and antioxidant capacity using two different assays. Although no significant differences were found in total phenolic contents and antioxidant capacity, the Flavone, Flavonol, Flavonoid, and Phenylpropanoid Biosynthesis pathway was significantly higher in the Romana rather than in the Giffoni variety, whereas Myricetin and Syringetin compounds were more representative in Giffoni cultivars. These results indicated that hazelnut skin, especially from the Romana variety, could potentially be used as an ingredient in healthy food. Healthy food is a new food category with an expanding demand from future generations.
\end{abstract}

Keywords: hazelnut skin; untargeted metabolomic; phenolic compounds; nutraceuticals

\section{Introduction}

A sustainable future for the human race must include the effective reuse and recycling of waste streams. Wastes are generally considered worthless at the time of production, yet they can still contain resources that may become valuable [1]. In the whole food production chain, from industry to the fork, food manufacturing steps have a large environmental impact, as $\sim 30-50 \%$ of produced foods become waste [2]. The development of green technologies in the food manufacturing sector is particularly relevant with the objective to convert raw agro materials into food products with the desired quality and functional properties while increasing manufacturing efficiency [3]. The wastes generated from the processing of various plant-based foods are rich in sugars, pectin, proteins, lipids, polysaccharides, fibers, flavor compounds, and phytochemicals. Such value-added products have immense value as food additives, nutraceuticals, therapeutics, cosmetics, etc. [4,5]. Natural ingredients recovered from agro-industrial by-products have specific dietary and functional properties and can be utilized effectively to develop this new food category. In this context, we considered them in our manuscript hazelnut. This nut belongs to the family Betulaceae [6], and was determined to be a "heart-healthy" food [7] by Food and Drug Administration (FDA) and recommended in a balanced diet due their health-promoting properties. The seed is covered by a dark brown pellicular pericarp 
(skin or testa) [8] and is marketed as natural and processed kernels. Whole processed hazelnut kernels, which are called roasted hazelnuts, constitute the largest quantity of hazelnut consumption $[9,10]$. Hazelnut skin, which represents about $2.5 \%$ of the total hazelnut kernel weight, is removed during roasting, and has very low economic value, has traditionally been used for livestock feed and as a raw material for energy production. Hazelnut skins have a significant portion of polyphenols that can have covalent or strong non-covalent associations with plant proteins and polysaccharides [11]. Moreover, hazelnut skin is a rich source of dietary fiber as well as of natural antioxidants owing to the presence of phenolic compounds [6]. Recent research by Ozyurt et al. [10], determined total phenolic content to identify the total antioxidant activity to characterize the phenolic profile of hazelnut skin. Additionally, Contini et al. [12] verified the presence of tannin compounds obtained from phenolic extracts of hazelnut shell and skin wastes. Therefore, the usage of hazelnut skin as a source of antioxidants and dietary fiber may offer beneficial supplements to the food, medicine, and cosmetic industries [7]. The phenolic compounds play a role in human health promotion, disease risk reduction $[13,14]$, and providing protection against the harmful effects of free radicals, which impose the risk of cancer, stroke, inflammation, and other neurodegenerative diseases [15,16]. Indeed, hazelnut has a clear territorial characterization, and are redistributed in a few countries [17]. Hazelnut is a nut species cultivated in temperate climates such as those of the Black Sea coast of Turkey, hilly areas of Italy, northern regions of Spain, and Willamette Valley in Oregon, USA [18]. A mild climate, high rainfall, and cool summers are favorable characteristics and Italian varieties are currently qualified for protected geographical indication (PGI) (i.e., 'Tonda Gentile delle Langhe' e 'Tonda Gentile Romana') or protected designation of origin (PDO) ('Tonda di Giffoni') certifications. Italy is the second largest producer of hazelnuts $(13 \%)$ after Turkey [19]. Italy's Latinum regions contain more than $25 \%$ of the national production areas, concentrated in the Viterbo province as a typical hazelnut-growing area. Current research highlights the utility of metabolomics as high-throughput methods to profile variations in nutrients and bioactive compounds in foods. In the last few years, metabolomics has emerged as a new powerful approach, focusing on the comprehensive analysis of small-molecule metabolites in biological systems [20]. Moreover, multivariate analysis on metabolomics-based data allows gaining information directly correlated to food quality, safety, processing, storage, and authenticity assessments [21]. Hence, this study aimed to evaluate the differences between two varieties of hazelnut skin through a procedure able to detect a wide variety of metabolites from Tonda Gentile Romana and Tonda di Giffoni varieties coming from our geographic area. To ensure broad metabolite detection coverage on skin samples, we employed hydrophilic interaction liquid chromatography (HILIC), electrospray ionization-mass spectrometry (ESI-MS), a technology particularly suitable to separate samples and complex mixtures. Applying this experimental approach, one could identify the metabolites that characterize the two varieties.

\section{Results and Discussion}

The main purpose of this work was to analyze the global metabolite profile of skin coming from the industrial pericarp removal during the processing of whole or chopped hazelnut kernels. To achieve this aim, we analyzed the phenolic profiles and total antioxidant activities in two varieties of hazelnut by-products: Tonda Gentile Romana and Tonda di Giffoni. The content of total phenols ranged from $155.3 \pm 2.1 \mathrm{mg}$ GAE /g DW in Giffoni hazelnut skin to $153.3 \pm 3.9 \mathrm{mg}$ GAE / g DW in Romana hazelnut skin; the content of total flavonoids ranged from $27.2 \pm 0.7 \mathrm{mg} R E / g$ DW in Giffoni skin to $27.8 \pm 2.3 \mathrm{mg}$ RE /g DW in Romana skin (Table 1). Del Rio and coworkers (2011) [22] reported that the phenol content in aqueous extracts was $8.7 \pm 0.3 \mathrm{~g} / 100 \mathrm{~g}$ in Giffoni skin and $9.0 \pm 0.0$ in Romana skin; Contini and collaborators (2008) [12], showed that phenol content in methanol extract carried out on different varieties (Italian Tonda Gentile Romana, Tonda di Giffoni, Tonda Gentile delle Langhe, Turkish Tombul) was $426.7 \pm 4.6 \mathrm{mg}$ GAE/g. Since the antioxidant compounds in foods are chemically different and structurally complex, no single assay is 
suitable to accurately determine the antioxidant activity for all compounds. For this reason, antioxidant activity was determined in our study using two different antioxidant assays: FRAP and TEAC ABTS. The FRAP assay is based on an electron transfer mechanism without the involvement of free radicals, while TEAC ABTS assay is based on the conversion of oxidized $\mathrm{ABTS}^{\bullet+}$ radicals to ABTS via a hydrogen atom transfer (HAT) or single electron transfer (SET) mechanism. The antioxidant capacity ranged from $13.2 \pm 0.1 \mathrm{mM}$ TE in Giffoni hazelnut skin to $13.1 \pm 0.2 \mathrm{mM}$ TE in Romana hazelnut skin with the TEAC method and to $23.3 \pm 5.8 \mathrm{mM}$ TE in Giffoni skin to $23.1 \pm 6.2 \mathrm{mM}$ Te in Romana skin with the FRAP method (Table 1). Contini and collaborators (2008) [12], showed that the antioxidant capacity in methanol was $68 \pm 1.2 \mathrm{mg} \mathrm{GAE} / \mathrm{mg}$ DPPH); Del Rio and coworkers (2011) [22] reported that antioxidant capacity was $1321.1 \pm 54.4 \mathrm{mmol} \mathrm{Fe}{ }^{2+}$ Equivalent $/ \mathrm{kg}$ in Giffoni and $1229.9 \pm 47.0 \mathrm{Fe}^{2+}$ Equivalent $/ \mathrm{kg}$ in Romana. The difference in phenolics content and antioxidant capacity could depend on the extraction methods/solvents used and on environmental factors. The proximate composition of hazelnut skin is given in Table 2. Moisture, protein, and ash contents of the skins are shown on a dry weight (dw) basis and they are similar to reported data [23]. The lipid content is in the range of $18.4-26.4 \%$ from Giffoni skin (18.4\%) to Romana skin $(26.4 \%)$. Carbohydrates are the major components of skin; these results are in agreement with other studies [23]. Our results showed that the total phenols and flavonoids between varieties do not undergo variations, any difference likely lies in the phenol types. To verify the metabolomic differences between the varieties and eventually to the characterized phenol compounds, a more sensitive method consisting of UHPLC system coupled online with a Q Exactive mass spectrometer analysis was performed following a statistical multivariate analysis. Because significant amounts of data are obtained through metabolomic analysis, they must be interpreted. Chemometric methods help manage this enormity of information. For this purpose and to highlight the most significant differences among the metabolites between the two groups, we performed statistical analyses through Metaboanalyst v 4.0 (Wishart research Group at the University of Alberta, Edmonton, AB, Canada).

Table 1. TE, GAE and RE of hazelnuts skin. Total antioxidant capacity of hazelnut skins (TE Trolox equivalent), total polyphenols contents (GAE Gallic Acid Equivalent), total flavonoids contents (RE Rutin Equivalent).

\begin{tabular}{|c|c|c|c|c|}
\hline \multirow{2}{*}{ Varieties } & \multicolumn{2}{|c|}{ Antioxidant Capacity } & \multirow{2}{*}{$\begin{array}{c}\text { Polyphenols } \\
\text { mg/g GAE }\end{array}$} & \multirow{2}{*}{$\begin{array}{c}\text { Flavonoids } \\
\mathrm{mg} / \mathrm{g} \text { RE }\end{array}$} \\
\hline & TEAC mM TE & FRAP $\mathrm{mM}$ TE & & \\
\hline Tonda di Giffoni & $13.2 \pm 0.1^{a}$ & $23.3 \pm 5.8^{a}$ & $155.3 \pm 2.1^{\mathrm{a}}$ & $27.2 \pm 0.7^{\mathrm{a}}$ \\
\hline Tonda Gentile Romana & $13.1 \pm 0.2^{\mathrm{a}}$ & $23.1 \pm 6.2^{a}$ & $153.3 \pm 3.9^{a}$ & $27.8 \pm 2.3^{a}$ \\
\hline
\end{tabular}

Means $\pm \mathrm{SD}(n=9)$ followed by the same letter $\left({ }^{\mathrm{a}},{ }^{\mathrm{b}}\right)$ within a column are not significantly different $(p>0.05)$.

Table 2. Proximate composition of hazelnut skins.

\begin{tabular}{cccccc}
\hline \multirow{2}{*}{ Varieties } & Moisture & Ashes & Lipids & Proteins & Carbohydrates \\
\cline { 2 - 6 } & \% (g/100 g) & g/100 g DW & g/100 g DW & g/100 g DW & g/100 g DW \\
\hline Tonda di Giffoni & $4.7 \pm 0.2^{\mathrm{a}}$ & $3.0 \pm 0.02^{\mathrm{a}}$ & $18.4 \pm 0.1^{\mathrm{b}}$ & $7.5 \pm 0.2^{\mathrm{a}}$ & $71.1 \pm 0.3^{\mathrm{a}}$ \\
\hline Tonda Gentile Romana & $4.1 \pm 0.1^{\mathrm{a}}$ & $2.8 \pm 0.02^{\mathrm{a}}$ & $26.4 \pm 0.1^{\mathrm{a}}$ & $8.9 \pm 0.3^{\mathrm{a}}$ & $61.9 \pm 0.2^{\mathrm{b}}$ \\
\hline
\end{tabular}

Means $\pm \mathrm{SD}(n=3)$ followed by the same letter $\left(\begin{array}{c}\mathrm{a} \\ ,\end{array}\right)$ within a column are not significantly different $(p>0.05)$. DW (dry weight).

The principal component analysis (PCA) showed a clear separation of Romana from Giffoni skin (Figure 1), with $57.6 \%$ of the variance captured by the first two PCs. To confirm PCA results with a more powerful pattern recognition method, we performed a supervised PLS-DA (Partial Least Squares Discriminant Analysis). Satisfactory modeling and prediction results were already gained with three PCs (Accuracy 0.94444, $\mathrm{R}^{2}>0.99944$, $\mathrm{Q}^{2}>0.93344$ ) (Supplementary Materials Figure S1). Metabolomic analysis was conducted through two strategies that are complementary to each other. The first gave overall 
metabolic changes without going to analyze the concentrations of the metabolites present to obtain a global view. Table 3 obtained by using MAVEN lists the major metabolites differentially expressed in the two Tonda Gentile Romana and Tonda di Giffoni varieties. MAVEN is an open-source cross-platform metabolomics data analyzer. The purpose of this software package is to reduce the complexity of metabolomics analysis by incrementing a high instituted interface for examining and validating metabolomics data. The program features multi-file chromatographic aligners, peak-feature detector, an isotope and adduct calculator, formula predictor, pathway visualizer, and isotopic flux animator. From this table, several compounds were identified such as flavonoids (eriodictyol, quercetin, kaempferol, rutin), phenolic acids (neochlorogenic acid, caffeic acid, coumaric acid) flavan3-ols (catechin, myricetin) and other compounds, these results are comparable to those obtained by Del Rio [22]. Moreover, MAVEN supports data from ESI-MS. To better identify which metabolic pathways were most affected in these two species, we used the bioinformatics Metabolomics Pathway Analysis (MetPA) by MetaboAnalyst 4.0, which combines the results from the pathway enrichment analysis with the pathway topology analysis (Figure 2). The "metabolome overview" obtained through metabolic pathway analysis (MetPA) showed that the Flavonoid and Phenylpropanoid biosynthesis were significantly perturbed (FDR < 0.05; pathway impact value > 0.2) between Tonda Gentile Romana and Tonda di Giffoni variety and we focused our attention on these two pathways. To this aim, we applied a second investigation strategy called "metabolic profiling" that allowed us to conduct qualitative and quantitative analysis of the individual metabolites. Figure 3 shows the quantitative and qualitative variations among metabolites belonging to the biosynthesis of flavonoids between the two varieties. Quercetin, which is the main representative metabolite of the Flavonol Biosynthesis, was significantly increased in Giffoni skin. Quercetin, the aglycone structure of rutin, is one of the most prominent dietary antioxidants; quercetin has many molecular and physiological effects in various organisms, including humans; it may have key roles in combating asthma, diabetes, obesity, cardiovascular, neurological, and inflammatory diseases [24] and cancer [25]. Due to the biological and pharmacological importance of quercetin as a bioactive flavonoid, we commonly consider the Giffoni skin to be more useful for sources of nutritional and therapeutic purposes. Quercetin is present in plants in many different glycosidic forms. It is usually found in conjugated forms with sugars such as glucose, galactose, and rhamnose [26]. Rutin, chemically, is a glycoside composed of the flavonol aglycone quercetin along with the disaccharide rutinose. The "metabolic profiling" in Figure 3 showed that rutin was significantly increased in Romana skin. Rutin has demonstrated a number of pharmacological activities, including antioxidant, cytoprotective, vasoprotective, anticarcinogenic, neuroprotective, and cardioprotective activities [27-34]. Rutin which is one of the best natural antioxidants in the known natural class, is absorbed more slowly than quercetin because it must first be hydrolyzed by the gut microbiota, whereas quercetin is absorbed from the small intestine. The prevalent forms are quercetin conjugated with one or two glucose molecules, such as isoquercetin and quercetin conjugated with rutinose such as quercetin, rutinoside rutin, and quercetin 3-o-glucoside that we found to be significantly upregulated in Romana species (Figure 3). Moreover, quercetin 3-o-glucoside exhibits more anti-inflammatory action than other forms of quercetin [35]. Thus, the higher level of these two metabolites shown in Romana cultivars led to believe that this species could have more healthy properties than Giffoni. Besides the biosynthesis of flavonoids, the phenylpropanoid biosynthesis is altered between the two varieties. In addition, in this case in the Romana variety, the intermediates of the metabolism of phenylpropanoids were found to be increased, as shown in Figure 4 . Many biological activities of Phenylpropanoid biosynthesis (Figure 4) are attributed to ester derivatives of caffeic acid (strongly active in Romana) such as anti-inflammatory, anti-cancer by induction of apoptosis, antimicrobial, and immunomodulatory activity. Several studies have shown that caffeic acid and ferulic acid can inhibit the oxidation of low-density lipoprotein (LDL) in vitro [36-38]. Furthermore, caffeic acid is absorbed in rats and has an absolute bioavailability in humans of around 95\% [39,40]. Finally, appropriate 
model validation is a crucial step to assess reliability for quantitative or confirmatory purposes. Based on these results, we moved from targeted to untargeted mass spectrometric methods and we quantified the principal phenolic compounds of phenylpropanoid pathways using authentic standards (Table 4 ) to demonstrate if they were effectively present in quantities that enable consideration of hazelnut skin as a beneficial food for health Notably, the quantity of the flavonoids detected is remarkably high, enabling hazelnut skin to be considered useful as an antioxidant. The concentration of quercetin is higher in the Giffoni, while the concentration of rutin is higher in the Romana. In particular, the antioxidant capacity of various nuts and their byproducts has been widely investigated, and several works have acknowledged that nut byproducts are especially rich sources of natural phenolic compounds with potential bioactivities [41,42]. Here, we considered two local varieties in an attempt to add economic value to waste from the hazelnut industry. However, we also consider it necessary to examine the bioavailability of these compounds after the digestion process, with the aim of clarifying the effective bioavailability of the hazelnut skin constituents (paper in preparation).
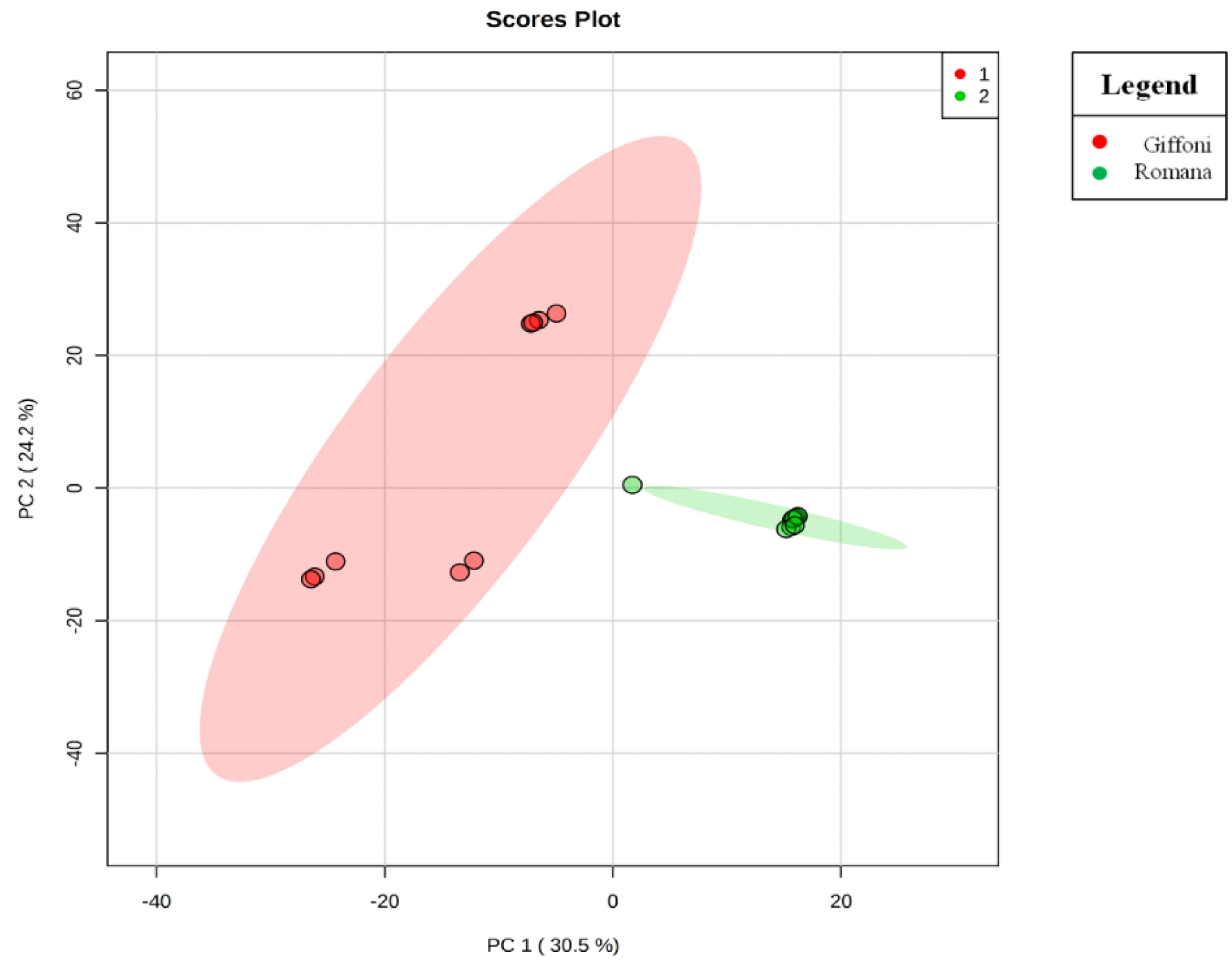

Figure 1. Principal component analysis (PCA) scores plot. The PCA scores plot shows a clear segregation of Tonda di Giffoni and Romana samples, indicating that Tonda di Giffoni and Tonda Gentile Romana have different metabolic profiles. 
Table 3. Mass Spectral Characteristics of Phenolics Identified in Methanol Extract of Hazelnut Skins.

\begin{tabular}{|c|c|c|c|c|c|}
\hline Compound & $\begin{array}{c}m / z \\
(\mathrm{~g} / \mathrm{mol})\end{array}$ & $\begin{array}{l}\text { Tonda di } \\
\text { Giffoni }\end{array}$ & DEV.SD & $\begin{array}{c}\text { Tonda Gentile } \\
\text { Romana }\end{array}$ & DEV. SD \\
\hline Chlorflavonin & 378.8 & $3.32 \times 10^{4}$ & $2.29 \times 10^{4}$ & $3.54 \times 10^{4}$ & $7.78 \times 10^{3}$ \\
\hline Flavonol 7-O-beta-D-glucoside & 416.41 & $1.03 \times 10^{6}$ & $2.10 \times 10^{6}$ & $9.68 \times 10^{4}$ & $1.66 \times 10^{4}$ \\
\hline Naringenin 7-O-beta-D-glucoside & 434.41 & $3.91 \times 10^{6}$ & $3.92 \times 10^{6}$ & $4.26 \times 10^{5}$ & $7.01 \times 10^{4}$ \\
\hline Leucocyanidin & 306.27 & $3.45 \times 10^{6}$ & $4.30 \times 10^{6}$ & $1.89 \times 10^{6}$ & $1.84 \times 10^{5}$ \\
\hline Caffeic acid 3-glucoside & 342.3 & $6.31 \times 10^{4}$ & $3.19 \times 10^{4}$ & $2.50 \times 10^{5}$ & $3.23 \times 10^{4}$ \\
\hline Epigallocatechin-(4beta->8)-epicatechin-3-O-gallate ester & 746.6 & $6.55 \times 10^{5}$ & $1.35 \times 10^{6}$ & $1.02 \times 10^{5}$ & $9.82 \times 10^{3}$ \\
\hline Kaempferol 3-O-beta-D-glucosylgalactoside & 610.5 & $8.40 \times 10^{5}$ & $1.75 \times 10^{6}$ & $5.26 \times 10^{4}$ & $8.20 \times 10^{3}$ \\
\hline Vitexin 2-O-beta-D-glucoside & 593.5 & $6.18 \times 10^{5}$ & $1.31 \times 10^{6}$ & $8.82 \times 10^{4}$ & $1.23 \times 10^{4}$ \\
\hline Kaempferitrin & 578.5 & $1.74 \times 10^{6}$ & $2.80 \times 10^{6}$ & $7.32 \times 10^{5}$ & $2.05 \times 10^{6}$ \\
\hline$(-)$-Catechin & 290.27 & $1.93 \times 10^{7}$ & $2.11 \times 10^{7}$ & $6.31 \times 10^{7}$ & $9.78 \times 10^{6}$ \\
\hline Flavin & 453.3 & $2.15 \times 10^{6}$ & $2.40 \times 10^{6}$ & $1.93 \times 10^{5}$ & $1.56 \times 10^{4}$ \\
\hline n-Propyl gallate & 212.2 & $3.77 \times 10^{6}$ & $3.75 \times 10^{6}$ & $4.03 \times 10^{6}$ & $7.47 \times 10^{5}$ \\
\hline Methyl caffeate & 194.18 & $1.01 \times 10^{6}$ & $8.16 \times 10^{5}$ & $1.44 \times 10^{6}$ & $2.40 \times 10^{5}$ \\
\hline Laricitrin & 332.26 & $1.86 \times 10^{5}$ & $4.56 \times 10^{4}$ & $2.41 \times 10^{5}$ & $5.02 \times 10^{4}$ \\
\hline Syringetin & 346.3 & $8.81 \times 10^{4}$ & $1.32 \times 10^{4}$ & $5.22 \times 10^{4}$ & $6.87 \times 10^{3}$ \\
\hline Apigenin & 270.24 & $5.72 \times 10^{6}$ & $1.31 \times 10^{6}$ & $4.69 \times 10^{6}$ & $7.24 \times 10^{5}$ \\
\hline Kaempferol & 286.24 & $1.06 \times 10^{6}$ & $2.52 \times 10^{5}$ & $2.13 \times 10^{6}$ & $4.12 \times 10^{5}$ \\
\hline Caffeate & 180.16 & $3.67 \times 10^{5}$ & $5.69 \times 10^{4}$ & $6.77 \times 10^{5}$ & $8.26 \times 10^{4}$ \\
\hline 3-Coumaric acid & 164.16 & $2.46 \times 10^{6}$ & $3.65 \times 10^{5}$ & $2.56 \times 10^{6}$ & $3.86 \times 10^{5}$ \\
\hline Neochlorogenic acid & 354.31 & $3.52 \times 10^{5}$ & $6.34 \times 10^{4}$ & $1.80 \times 10^{4}$ & $2.90 \times 10^{3}$ \\
\hline Salicylate & 137.11 & $5.15 \times 10^{7}$ & $9.23 \times 10^{6}$ & $2.85 \times 10^{7}$ & $5.83 \times 10^{6}$ \\
\hline Vitexin & 432.4 & $1.91 \times 10^{6}$ & $3.80 \times 10^{5}$ & $3.30 \times 10^{6}$ & $6.04 \times 10^{5}$ \\
\hline Astragalin & 448.4 & $1.45 \times 10^{7}$ & $1.48 \times 10^{6}$ & $2.57 \times 10^{7}$ & $2.67 \times 10^{6}$ \\
\hline Quercetin 3-O-glucoside & 464.4 & $1.23 \times 10^{6}$ & $8.96 \times 10^{5}$ & $3.20 \times 10^{6}$ & $3.99 \times 10^{5}$ \\
\hline Naringenin & 272.25 & $4.83 \times 10^{6}$ & $1.06 \times 10^{6}$ & $5.77 \times 10^{6}$ & $1.07 \times 10^{6}$ \\
\hline Eriodictyol & 288.25 & $3.73 \times 10^{6}$ & $3.30 \times 10^{5}$ & $7.03 \times 10^{6}$ & $8.10 \times 10^{5}$ \\
\hline Luteoforol & 290.27 & $4.15 \times 10^{7}$ & $6.45 \times 10^{6}$ & $6.60 \times 10^{7}$ & $1.01 \times 10^{7}$ \\
\hline Ferulate & 194.18 & $1.61 \times 10^{6}$ & $3.04 \times 10^{5}$ & $1.47 \times 10^{6}$ & $2.32 \times 10^{5}$ \\
\hline Sinapate & 224.21 & $1.35 \times 10^{6}$ & $7.66 \times 10^{5}$ & $5.31 \times 10^{6}$ & $7.88 \times 10^{5}$ \\
\hline Sinapine & 310.36 & $1.43 \times 10^{5}$ & $3.07 \times 10^{4}$ & $4.68 \times 10^{5}$ & $8.39 \times 10^{4}$ \\
\hline 4-Hydroxystyrene & 120.15 & $2.65 \times 10^{7}$ & $3.53 \times 10^{6}$ & $1.07 \times 10^{8}$ & $1.34 \times 10^{7}$ \\
\hline Salicylaldehyde & 122.12 & $4.84 \times 10^{6}$ & $8.03 \times 10^{5}$ & $9.72 \times 10^{6}$ & $1.19 \times 10^{6}$ \\
\hline Isochorismate & 224.17 & $3.77 \times 10^{5}$ & $1.01 \times 10^{5}$ & $1.48 \times 10^{5}$ & $1.79 \times 10^{4}$ \\
\hline Salicin & 286.28 & $4.12 \times 10^{5}$ & $4.67 \times 10^{5}$ & $6.24 \times 10^{5}$ & $9.80 \times 10^{4}$ \\
\hline 2-3-Dihydroxybenzoate & 153.11 & $1.34 \times 10^{7}$ & $1.53 \times 10^{6}$ & $6.16 \times 10^{6}$ & $8.50 \times 10^{5}$ \\
\hline p-Coumaroyl quinic acid & 338.31 & $2.58 \times 10^{6}$ & $2.83 \times 10^{6}$ & $1.93 \times 10^{5}$ & $3.59 \times 10^{4}$ \\
\hline Naringin chalcone & 580.5 & $1.46 \times 10^{6}$ & $1.12 \times 10^{6}$ & $7.10 \times 10^{5}$ & $1.14 \times 10^{5}$ \\
\hline Kaempferide & 300.26 & $8.11 \times 10^{4}$ & $4.59 \times 10^{4}$ & $3.24 \times 10^{5}$ & $6.81 \times 10^{4}$ \\
\hline Quercetin & 302.2 & $8.58 \times 10^{6}$ & $1.94 \times 10^{6}$ & $5.10 \times 10^{6}$ & $1.01 \times 10^{6}$ \\
\hline Rutin & 610.5 & $2.94 \times 10^{5}$ & $1.08 \times 10^{5}$ & $9.86 \times 10^{5}$ & $2.05 \times 10^{5}$ \\
\hline Myricetin & 318.23 & $1.04 \times 10^{6}$ & $1.92 \times 10^{5}$ & $2.36 \times 10^{5}$ & $3.51 \times 10^{4}$ \\
\hline
\end{tabular}

Means $\pm \mathrm{SD}(n=9)$. Data are represented as peak intensity.

Table 4. List of phenolic compounds quantified using LC-MS. Means $\pm \operatorname{SD}(n=9)$. Compounds followed by the same letter $(\stackrel{\mathrm{a}}{,})$ within a row are not significantly different $(p>0.05)$.

\begin{tabular}{ccc}
\hline Phenolic Compound & Tonda di Giffoni & Tonda Gentile Romana \\
\hline & $\mathbf{~} \mathbf{g} / \mathbf{1 0 0} \mathbf{g}$ & $\mathbf{~} \mathbf{g} / \mathbf{1 0 0} \mathbf{g}$ \\
\hline Quercetin & $1.4 \pm 0.07^{\mathrm{a}}$ & $0.8 \pm 0.01^{\mathrm{b}}$ \\
Rutin & $0.4 \pm 0.04^{\mathrm{b}}$ & $0.8 \pm 0.01^{\mathrm{a}}$ \\
Vitexin & $2.5 \pm 0.1^{\mathrm{b}}$ & $3.9 \pm 0.4^{\mathrm{a}}$ \\
Caffeic Acid & $0.6 \pm 0.05^{\mathrm{a}}$ & $0.7 \pm 0.05^{\mathrm{a}}$ \\
P-Coumeric Acid & $0.7 \pm 0.08^{\mathrm{a}}$ & $0.7 \pm 0.06^{\mathrm{a}}$ \\
\hline
\end{tabular}




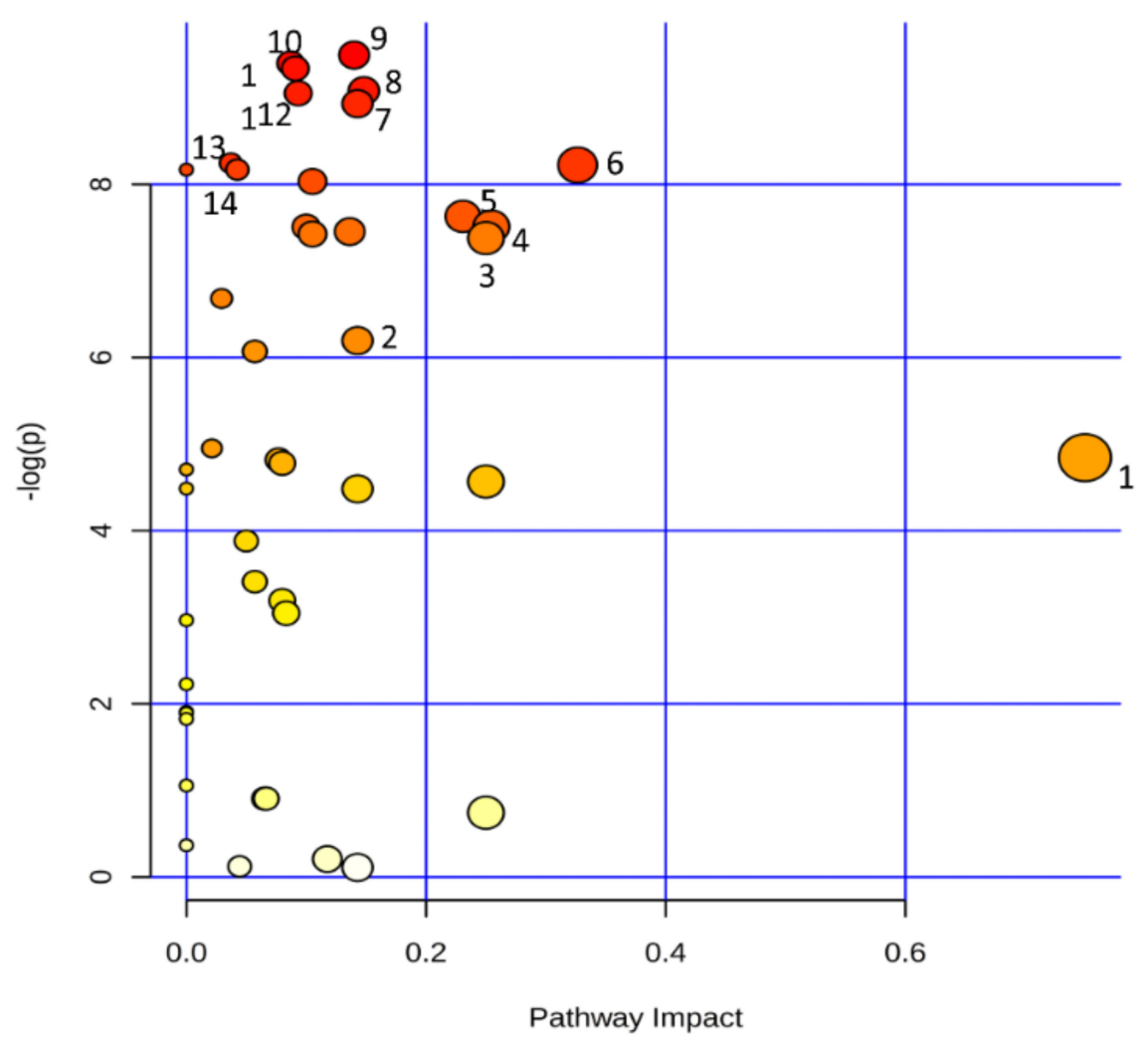

1. Flavone and flavonol biosynthesis

2. Glycerophospholipid metabolism

3. Histidine metabolism

4. Phenylalanine metabolism

5. Phenylpropanoid metabolism

6. Flavonoid biosynthesis

7. Arginine and proline metabolism

8. Amminoacyl-tRNA biosynthesis

9. Glucosinolate biosynthesis

10. Tryptophan metabolism

11. Glutathione metabolism

12. Purine metabolism

13. Glycerolipid metabolism

14. Arginine biosynthesis

Figure 2. Metabolic Pathway Analysis (MetPA). All the matched pathways are displayed as circles. The colour and size of each circle are based on the $p$-value and pathway impact value, respectively. The graph was obtained by plotting the - log of $p$ values from the pathway enrichment analysis on the $y$-axis and the pathway impact values derived from the pathway topology analysis on the $\mathrm{x}$-axis. 


\section{FLAVONOL BIOSYNTHESIS}
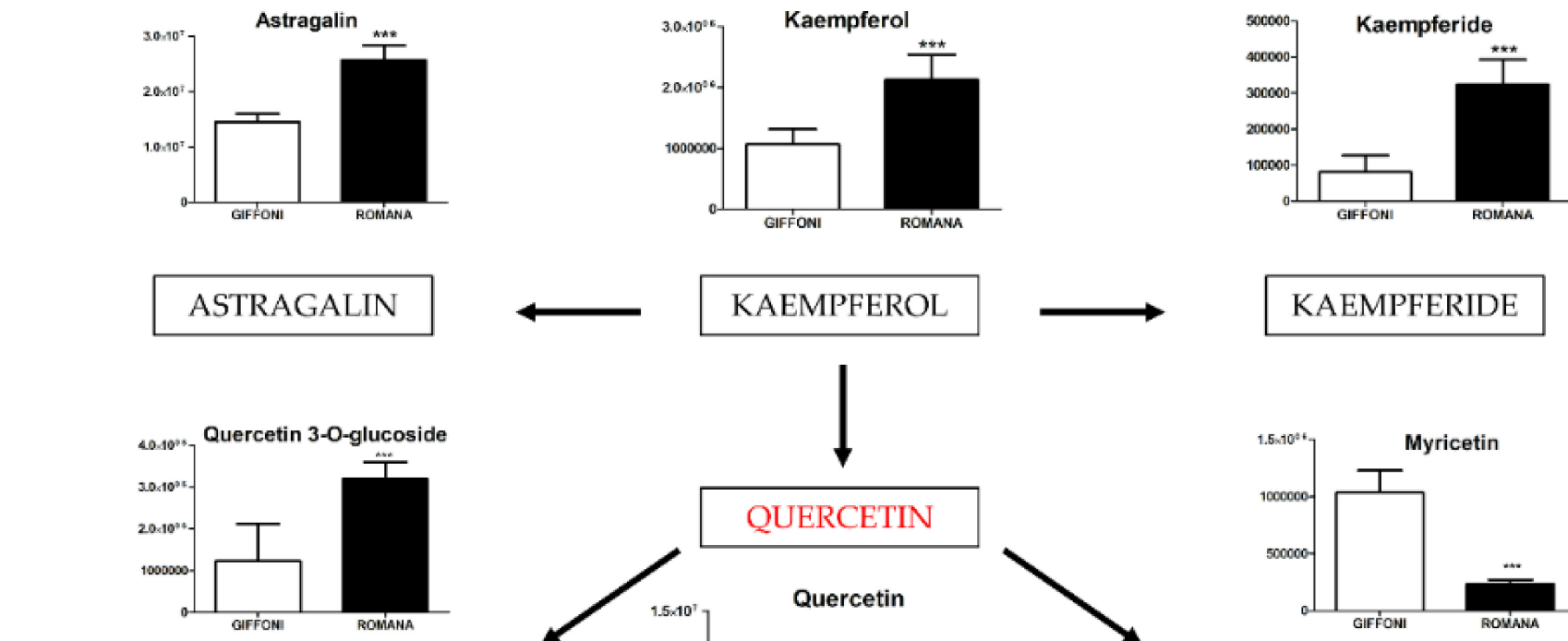

\section{KAEMPFERIDE}
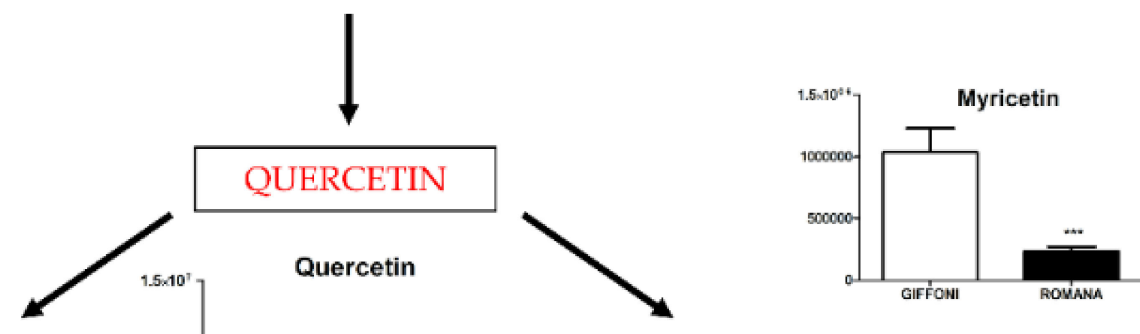

\section{QUERCETIN-3-O-GLUCOSIDE}

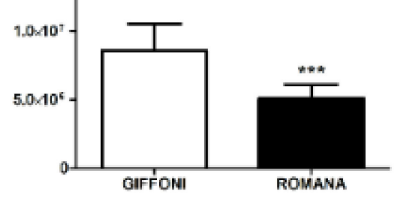

MYRICETIN
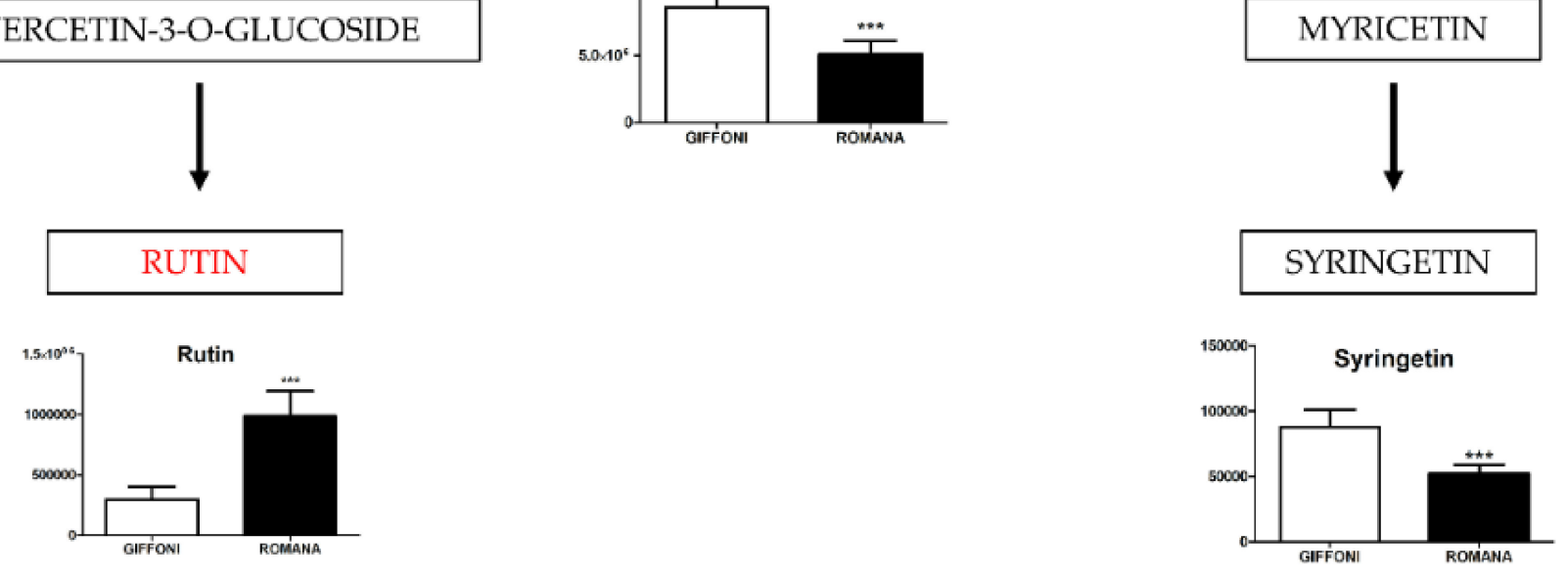

Figure 3. The level of metabolites involved in the Flavonol biosynthesis were analyzed in Giffoni and Romana hazelnut skin. Values are presented as the mean \pm SD. ${ }^{* * *}(p \leq 0.001)$. 


\section{PHENILPROPANOID BIOSYNTHESIS}
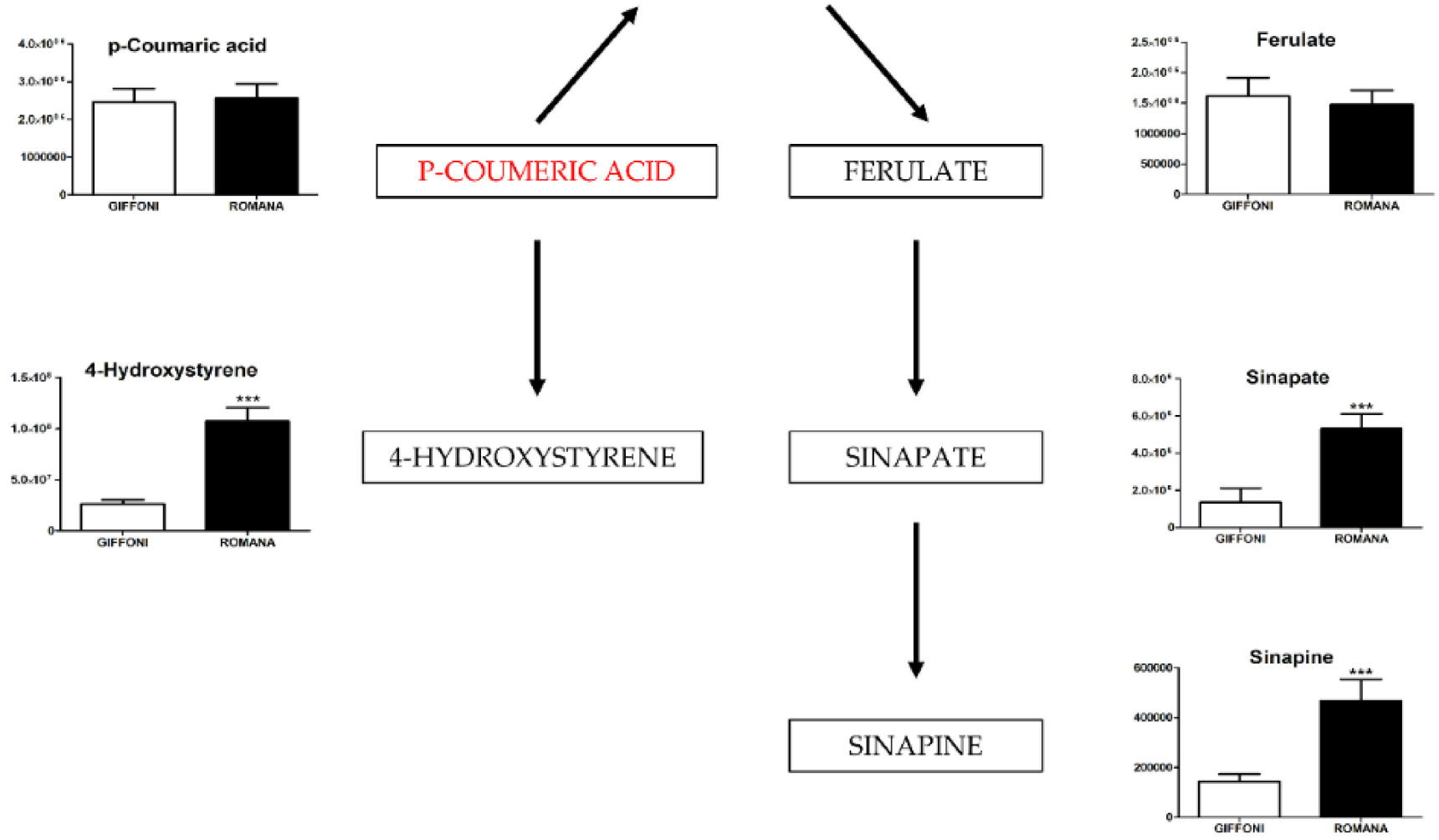

Figure 4. The figure represents metabolites involved in the Phenilpropanoid biosynthesis found in different concentrations in the two varieties of hazelnut skin. Data are presented as the mean \pm SD. ${ }^{* * *}(p \leq 0.001)$.

\section{Materials and Methods}

\subsection{Raw Materials and Extract Preparation}

Hazelnut skins (Tonda Gentile Romana and Tonda di Giffoni variety) were obtained from a local producer (Bionocciola srl, Carbognano, Viterbo, Italy) after roasting hazelnuts at $150{ }^{\circ} \mathrm{C}$ for $24 \mathrm{~min}$. To measure the antioxidant activity, total polyphenol, and total flavonoid contents, $0.5 \mathrm{~g}$ of two varieties of Tuscia hazelnut skins were extracted with a solvent consisting of methanol:water $(80: 20, v / v)$ in a ratio 1:20. A total of $20 \mathrm{mg}$ of two varieties of Tuscia hazelnuts skins were used for metabolomics analysis. The 1:25 mixture was shaken at room temperature for $2 \mathrm{~h}$, and then centrifuged at $1000 \times g$ for $10 \mathrm{~min}$, the supernatant was used for all analyses. All chemicals used were of analytical grade and were purchased from Sigma Aldrich (Milano, Italy). Stock standard solutions of phenolic compounds were prepared by rigorous dissolution of the commercial reagent in methanol. High-purity water from a Direct-Q 3 UV water purification system (Millipore, Burlington, MA, USA) was used for all analyses. 


\subsection{Determination of Total Phenols}

Total phenols were determined using a modification of the Folin and Ciocalteu standard method [43]. Briefly, the assay was conducted by mixing $4 \mathrm{~mL}$ of deionized water, $0.25 \mathrm{~mL}$ of extract, $0.25 \mathrm{~mL}$ of Folin Ciocalteu reagent, and $0.5 \mathrm{~mL}$ of $\mathrm{Na}_{2} \mathrm{CO}_{3}$. After employing the Singleton pattern for $30 \mathrm{~min}$ at room temperature, the absorbance of the mixture was measured on the Uvikon spectrophotometer (942, Kontron Instruments, Zurich, Switzerland) at $725 \mathrm{~nm}$. A standard curve with gallic acid was prepared. The final results were expressed as mg of gallic acid equivalents (GAE)/ g of dry weight (DW). All analyses were conducted in nine replicates.

\subsection{Determination of Total Flavonoids}

The total flavonoid contents in the samples were determined using the aluminum chloride colorimetric method described by Qin et al. [44]. Briefly, the appropriate dilutions of the extract $(0.5 \mathrm{~mL})$ were mixed with $1.5 \mathrm{~mL}$ of $95 \%$ ethanol, $0.1 \mathrm{~mL}$ of $10 \%$ aluminum chloride hexahydrate $\left(\mathrm{AlCl}_{3} \times 6 \mathrm{H}_{2} \mathrm{O}\right), 0.1 \mathrm{~mL}$ of $1 \mathrm{M}$ potassium acetate $\left(\mathrm{CH}_{3} \mathrm{COOK}\right)$, and $2.8 \mathrm{~mL}$ of deionized water. After incubation at room temperature for $30 \mathrm{~min}$, the absorbance of the reaction mixture was measured at $415 \mathrm{~nm}$ with Uvikon spectrophotometer (942, Kontron Instruments, Zurich, Switzerland). The total flavonoid contents were expressed as mg rutin equivalents (RE)/g DW. Samples were analyzed in nine replicates.

\subsection{Measurements of Total Antioxidant Capacity Using FRAP and TEAC Assay}

A ferric reducing antioxidant power (FRAP) assay was performed according to the method described by Benzie and Strain [45], which was adapted for 96-well plates and an automatic reader. The method is based on the reduction of the $\mathrm{Fe}^{3+}-2,4,6$-tripyridyls-triazine (TPTZ) complex to its ferrous form at low pH. Briefly, $160 \mu \mathrm{L}$ of FRAP assay solution (consisting of $20 \mathrm{mM}$ ferric chloride solution, $10 \mathrm{mM}$ TPTZ solution, and $0.3 \mathrm{M}$ acetate buffer at $\mathrm{pH}$ 3.6) was prepared daily, mixed with $10 \mu \mathrm{L}$ of the sample, standard, or blank, and dispensed into each well of a 96-well plate. The absorbance was measured at $595 \mathrm{~nm}$ at $37^{\circ} \mathrm{C}$ after $30 \mathrm{~min}$ of incubation. All analyses were conducted in nine replicates. The final results are expressed as $\mathrm{mM}$ Trolox equivalents per $\mathrm{g}$ of the DW samples (mM TE/g DW). The TEAC assay (Trolox Equivalent Antioxidant Capacity) was performed using the OxiSelect TEAC Assay Kit (Cell Biolabs, San Diego, CA, USA) following the company protocol.

\subsection{Proximate Composition}

Moisture, ash, as well as protein, lipid, and carbohydrate contents in skin samples were determined according to the standard procedures of the Association of Official Analytical Chemists International [46]. The moisture and ash contents were determined using standard methods [45,46]. Total nitrogen and total protein contents (conversion factor: 6.25, AOAC 2007, 2001.11) were obtained using Kjedahl digestion (BUCHI Auto Kjeldahl Unit K370 and BUCHI Speed Digester K439). Lipid fraction was extracted using a semiautomatic Soxhlet Buchi Extraction System B-811 (Buchi Labortechnic AG, Flawil, Switzerland) with petrol ether as the extraction solvent (AOAC 2007, 920.39). Carbohydrate content was calculated by subtracting the contents of other compositions from $100 \%$.

\subsection{Analysis of Phenolic Compound Composition by LC-MS}

Untargeted metabolomics was applied to investigate the biochemical alterations of hazelnut skin. A total of 20 microliters of the extracted samples was injected into an Ultra HighPerformance Liquid Chromatography (UHPLC) system (Ultimate 3000, Thermo, Fisher Scientific, Waltham, MA, USA), which was operated in positive ion mode. A Reprosil C18 column $(2.0 \mathrm{~mm} \times 150 \mathrm{~mm}, 2.5 \mu \mathrm{m}$-Dr, Maisch, Germany) was used for metabolite separation. Chromatographic separations were made at a column temperature of $30^{\circ} \mathrm{C}$ and a flow rate of $0.2 \mathrm{~mL} / \mathrm{min}$. For positive ion mode (+) MS analyses, a $0-100 \%$ linear gradient of solvent $\mathrm{A}$ ( $\mathrm{ddH}_{2} \mathrm{O}, 0.1 \%$ formic acid) to $\mathrm{B}$ (acetonitrile, $0.1 \%$ formic acid) was employed over $20 \mathrm{~min}$, 
returning to $100 \% \mathrm{~A}$ in $2 \mathrm{~min}$ and holding solvent A for a 6-min post-time hold. Acetonitrile, formic acid, and HPLC-grade water and standards ( $\geq 98 \%$ chemical purity) were purchased from Sigma Aldrich. The UHPLC system was coupled online to a $Q$ Exactive mass spectrometer (Thermo) scanning in full MS mode ( $2 \mu$ scans) at a resolution of 70,000 in the 67 to $1000 \mathrm{~m} / \mathrm{z}$ range, a target of 1106 ions and a maximum ion injection time (IT) of $35 \mathrm{~ms}$ with $3.8 \mathrm{kV}$ spray voltage, 40 sheath gas, and 25 auxiliary gas. The system was operated in positive ion mode. Calibration was performed before each analysis with positive or negative ion mode calibration mixes to ensure error of the intact mass within the sub ppm range. Metabolite assignments were performed using computer software (Maven 18 Princeton, NJ, USA), upon conversion of raw files into a mzXML format using MassMatrix (Cleveland, OH, USA). MAVEN is an open-source software that could be freely downloaded from the official project website. To further explore the metabolic differences between the two cultivars, multivariate statistical analyses were employed using the MetaboAnalyst 4.0 software. Before the analysis, the raw data were normalized by sum and auto-scaling to increase the importance of low-abundance ions without a significant amplification of noise. The web-based tool MetPA (Metabolomic Pathway Analysis), which is incorporated into the MetaboAnalyst platform, was used to perform pathway analyses. Data for metabolites detected in all samples were submitted to MetPA with annotations based on common chemical names. Global test was the selected pathway enrichment analysis method, whereas the node importance measure for topological analysis was the relative betweenness centrality. Metabolites subject to major changes were graphed with Graphpad Prism 5.03 (Graphpad SoftwareInc, San Diego, CA, USA, 92108). Statistical analyses were performed with the same software. Data are means of nine replicates $\pm \mathrm{SD}$. Differences were considered statistically significant at ${ }^{*} p<0.05$ and further stratified to ${ }^{* *} p<0.01$ and ${ }^{* * *}$ $p<0.001$, respectively. For the analysis of antioxidant capacity, total phenol and flavonoids data are presented as mean \pm standard deviation of nine independent replicates. Statistical comparisons were made by one-way analysis of variance followed by Fisher's comparison test using the XLSTAT 2019 software (Addinsoft SARL, New York, NY, USA). Values were considered significant when $p<0.05$ [r1].

\subsection{Quantitative Analysis}

The flavonols were identified on the basis of their MS spectra and molecular-ion identification. Quantification of these compounds was calculated relative to the corresponding external standards from the calibration curves that covered the range from $0.002 \mathrm{mg} / \mathrm{mL}$ to $0.2 \mathrm{mg} / \mathrm{mL}$. Data are presented as the mean $\pm \operatorname{SD}^{*}(p \leq 0,05)$. For an initial evaluation of the calibration function, as part of the method validation, standards with different concentrations (including a blank) were prepared. The calibration range was established so that most sample concentrations fall within the range. Each study sample is divided into aliquots of equal volumes and known and variable amounts of the standard were added to the aliquots to construct the calibration curve. The calibration solutions were prepared from a pure substance with a known purity value. Commercial Standards: Quercetin $\geq 95 \%$ (HPLC), Rutin $\geq 94 \%$ (HPLC), p-Coumaric acid $\geq 98 \%$ (HPLC), Vitexin $\geq 95.0 \%$ (HPLC), and Caffeic Acid $\geq 98 \%$ (HPLC), were purchased from Sigma-Aldrich Co. (St. Louis, MO, USA).

\section{Conclusions}

In conclusion, we investigated the composition of byproducts of two hazelnut local varieties: Tonda Gentile Romana and Tonda di Giffoni, in an attempt to add economic value to waste from the hazelnut industry that could transform this waste into a precious renewable and natural resource. Metabolomics data revealed that Giffoni and Romana have distinct metabolic profiles. One of the significant differences between the two profiles was the polyphenols compounds, in particular Flavones, Flavonol, Flavonoid, and Phenylpropanoid biosynthesis, were found to be higher in Romana varieties, which supports the idea of the potential for new targets for health. Flavonoid and Phenylpropanoid biosynthesis pathways are significantly higher in Romana rather than in Giffoni varieties, whereas Myricetin and Syringetin compounds are more representative in Giffoni cultivars. 
Our results suggest that hazelnut skin can be used in the preparation of low calorie, high fiber, and antioxidant-rich foods, as well as food supplements, and active pharmaceuticals. Finally, the manuscript provides for the first time some new information regarding flavonoids in these hazelnut skins using LC-MS.

Supplementary Materials: The following are available online at https:/ /www.mdpi.com/article/10 $.3390 /$ metabo11050296/s1, Figure S1: Q2 is an estimate of the predictive ability of the model and is calculated via cross-validation $(\mathrm{CV})$. In each $\mathrm{CV}$, the predicted data are compared with the original data, and the sum of squared errors is calculated. The prediction error is then summed over all samples (Predicted Residual Sum of squares or PRESS). For convenience, the PRESS is divided by the initial sum of squares and subtracted from 1 to resemble the scale of the R2. Good predictions will have a low PRESS or high Q2.

Author Contributions: A.M.T. wrote the manuscript; V.L. performed the spectrophotometric analysis; R.M. performed the biochemical analysis, and N.M. made appropriate corrections. All authors have read and agreed to the published version of the manuscript.

Funding: Research reported in this publication was supported by: PRIN Prot. 2017XCXAFZ. Research project title: "Dissecting the molecular mechanisms underlying the pathogenesis of acute myeloid leukaemia".

Institutional Review Board Statement: Not applicable.

Informed Consent Statement: Not applicable.

Data Availability Statement: No new Data were created or analyzed in this study. Data sharing is not applicable to this article.

Conflicts of Interest: The authors declare no conflict of interest.

$\begin{array}{ll}\text { Abbreviation } \\ \text { DPPH } & \text { 2:2-diphenyl-1-picryl-hydrazyl-hydrate } \\ \text { DW } & \text { Dry Weight } \\ \text { ESI-MS } & \text { Electrospray Ionization- Mass Spectrometry } \\ \text { FDA } & \text { Food and Drug Administration } \\ \text { FDR } & \text { False Discovery Rate } \\ \text { FRAP } & \text { Ferric Reducing Antioxidant Power } \\ \text { GAE } & \text { Gallic Acid Equivalents } \\ \text { HAT } & \text { Hydrogen Atom Transfer } \\ \text { HILIC } & \text { Hydrophilic Interaction Liquid Chromatography } \\ \text { IT } & \text { Injection Time } \\ \text { LDL } & \text { Low-Density Lipoprotein } \\ \text { MetPA } & \text { Metabolomic Pathway Analysis } \\ \text { PCA } & \text { Principal Component Analysis } \\ \text { PCs } & \text { Principals Components } \\ \text { PDO } & \text { Protected Designation of Origin } \\ \text { PGI } & \text { Protected Geographical Indication } \\ \text { PLS-DA } & \text { Partial Least Squares Discriminant Analysis } \\ \text { RE } & \text { Rutin Equivalents } \\ \text { SET } & \text { Single Electron Transfer } \\ \text { TE } & \text { Trolox Equivalents } \\ \text { TEAC } & \text { Trolox Equivalent Antioxidant Capacity } \\ \text { TPTZ } & \text { Fe }{ }^{3+} \text {-2,4,6-tripyridyl-s-triazine } \\ \text { UHPLC } & \text { Ultra High-Performance Liquid Chromatography } \\ & \end{array}$

\section{References}

1. Bernd, G. Lottermoser. Recycling, Reuse and Rehabilitation of Mine Wastes. Elements 2011, 7, 405-410. [CrossRef]

2. Boye, J.I.; Arcand, Y. Current trends in green technologies in food production and processing. Food Eng. Rev. 2013, 5, 1-17. [CrossRef] 
3. Chemat, F.; Rombaut, N.; Meullemiestre, A.; Turk, M.; Perino, S.; Fabiano-Tixier, A.S.; Vian, M. Review of green food processing techniques. Preservation, transformation, and extraction. Innov. Food Sci. Emerg. Technol. 2013, 41, 357-377. [CrossRef]

4. Galanakis, C.M.; Tsatalas, P.; Galanakis, I.M. Phenols from olive mill wastewater and other natural antioxidants as UV filters in sunscreens. Environ. Technol. Innov. 2018, 9, 160-168. [CrossRef]

5. Galanakis, C.M.; Tsatalas, P.; Galanakis, I.M. Implementation of phenols recovered from olive mill wastewater as UV booster in cosmetics. Ind. Crops Prod. 2018, 111, 30-37. [CrossRef]

6. Alasalvar, C.; Karamac, M.; Kosinska, A.; Rybarczyk, A.; Shahidi, F.; Amarowicz, R. Antioxidant activity of hazelnut skin phenolics. J. Agric. Food Chem. 2009, 57, 4645-4650. [CrossRef]

7. Alasalvar, C.; Shahidi, F.; Liyanapathirana, C.M.; Ohshima, T. Turkish tombul hazelnut (Corylus avellana L.). 1. Compositional characteristics. J. Agric. Food Chem. 2003, 51, 3790-3796. [CrossRef]

8. Baş, F.; Ömeroğlu, S.; Türdü, S.; Aktaş, S. Önemli türk fındık çeşitlerinin bileşim özelliklerinin saptanması. GIDA 1986, 11. Available online: https:/ / dergipark.org.tr/tr/pub/gida/issue/6793/91377 (accessed on 1 August 1986).

9. Bezerra, M.A.; Santelli, R.E.; Oliveira, E.P.; Villar, L.S.; Escaleira, L.A. Response surface methodology (RSM) as a tool for optimization in analytical chemistry. Talanta 2008, 76, 965-977. [CrossRef]

10. Ozyurt, V.H.; Otles, S. Hazelnut testa as a by-product: Nutritional composition, antioxidant activity, phenolic compound profile and dietary fiber content. Ank. Univ. Eczacilik Fak. Derg. 2018, 42, 38-57. [CrossRef]

11. Le Bourvellec, C.; Renard, C.M. Interactions between polyphenols and macromolecules: Quantification methods and mechanisms. Crit. Rev. Food Sci. Nutr. 2012, 52, 213-248. [CrossRef] [PubMed]

12. Contini, M.; Baccelloni, S.; Massantini, R.; Anelli, A. Extraction of natural antioxidants from hazelnut (Corylus avellana L.) shell and skin wastes by long maceration at room temperature. Food Chem. 2008, 110, 659-669. [CrossRef]

13. Cory, H.; Passarelli, S.; Szeto, J.; Tamez, M.; Mattei, J. The Role of Polyphenols in Human Health and Food Systems: A Mini-Review. Front Nutr. 2018, 5, 87. [CrossRef] [PubMed]

14. Fraga, C.G.; Galleano, M.; Verstraeten, S.V.; Oteiza, P.I. Basic biochemical mechanisms behind the health benefits of polyphenols. Mol. Asp. Med. 2010, 31, 435-445. [CrossRef]

15. Lecour, S.; Lamont, K.T. Natural polyphenols and cardioprotection. Med. Chem. 2011, 11, 1191-1199. [CrossRef]

16. Crowe, K.M.; Francis, C. Position of the academy of nutrition and dietetics: Functional foods. J. Acad. Nutr. Diet. 2013, 113, 1096-1103. [CrossRef]

17. Locatelli, M.; Coisson, J.D.; Travaglia, F.; Cereti, E.; Garino, C.; D’Andrea, M.; Martelli, A.; Arlorio, M. Chemotype and genotype chemometrical evaluation applied to authentication and traceability of "Tonda Gentile Trilobata" hazelnuts from Piedmont (Italy). Food Chem. 2011, 129, 1865-1873. [CrossRef]

18. Solar, A.; Stampar, F. Characterisation of selected hazelnut cultivars: Phenology, growing and yielding capacity, market quality and nutraceutical value. J. Sci. Food Agric. 2011, 91, 1205-1212. [CrossRef]

19. Manfredi, M.; Robotti, E.; Quasso, F.; Mazzucco, E.; Calabrese, G.; Marengo, M. Fast classification of hazelnut cultivars through portable infrared spectroscopy and chemometrics. Spectrochim. Acta A 2018, 189, 427-435. [CrossRef]

20. Wishart, D.S. Metabolomics: Applications to food science and nutrition research. Trends Food Sci. Technol. 2008, 19, 482-493. [CrossRef]

21. Rocchetti, G.; Chiodelli, G.; Giuberti, G.; Ghisoni, S.; Baccolo, G.; Blasi, F.; Montesano, D.; Trevisan, M.; Lucini, L. UHPLC-ESIQTOF-MS profile of polyphenols in Goji berries (Lycium barbarum L.) and its dynamics during in vitro gastrointestinal digestion and fermentation. J. Funct. Foods. 2018, 40, 564-572. [CrossRef]

22. Del Rio, D.; Calani, L.; Dall'Asta, M.; Brighenti, F. Polyphenolic Composition of Hazelnut Skin. J. Agric. Food Chem. 2011, 59, 9935-9941. [CrossRef] [PubMed]

23. Özdemir, K.S.; Yılmaz, C.; Durmaz, G.; Gökmen, V. Hazelnut skin powder: A new brown colored functional ingredient. Food Res. Int. 2014, 65, 291-297. [CrossRef]

24. Romano, B.; Pagano, E.; Montanaro, V.; Fortunato, A.F.; Milic, N.; Francesca Borrelli, F. Novel Insights into the Pharmacology of Flavonoids. Phytother. Res. 2013, 27, 1588-1596. [CrossRef] [PubMed]

25. Tang, S.M.; Deng, X.T.; Zhoub, J.; Li, Q.P.; Ge, X.; Miao, L. Pharmacological basis and new insights of quercetin action in respect to its anti-cancer effects. Biomed. Pharmacother. 2020, 121, 109604. [CrossRef]

26. Vasantha-Rupasinghe, H.; Kathirvel, P.; Huber, G.M. Ultrasonication-assisted solvent extraction of quercetin glycosides from 'Idared' apple peels. Molecules 2011, 16, 9783-9791. [CrossRef] [PubMed]

27. Javed, H.; Khan, M.M.; Ahmad, A.; Vaibhav, K.; Ahmad, M.E.; Khan, A.; Ashafaq, M.; Islam, F.; Siddiqui, M.S.; Safhi, M.M.; et al. Rutin prevents cognitive impairments by ameliorating oxidative stress and neuroinflammation in rat model of sporadic dementia of Alzheimer type. Neuroscience 2012, 17, 340-352. [CrossRef]

28. Richetti, S.K.; Blank, M.; Capiotti, K.M.; Piato, A.L.; Bogo, M.R.; Vianna, M.R.; Bonan, C.D. Quercetin and rutin prevent scopolamine-induced memory impairment in zebrafish. Behav. Brain Res. 2011, 217, 10-15. [CrossRef]

29. Nassiri-Asl, M.; Hosseinzadeh, H. Review of the pharmacological effects of Vitis vinifera (Grape) and its bioactive compounds. Hytother. Res. 2010, 23, 1197-1204. [CrossRef]

30. Mellou, F.; Loutrari, H.; Stamatis, H.; Roussos, C.; Kolisis, F.N. Enzymatic esterification of flavonoids with unsaturated fatty acids: Effect of the novel esters on vascular endothelial growth factor release from K562 cells. Process Biochem. 2006, 41, 2029-3204. [CrossRef] 
31. Trumbeckaite, S.; Bernatoniene, J.; Majiene, D.; Jakstas, V.; Savickas, A.; Toleikis, A. The effect of flavonoids on rat heart mitochondrial function. Biomed. Pharmacother. 2006, 60, 245-248. [CrossRef] [PubMed]

32. Schwedhelm, E.; Maas, R.; Troost, R.; Böger, R.H. Clinical pharmacokinetics of antioxidants and their impact on systemic oxidative stress. Clin. Pharmacokinet. 2003, 42, 437-459. [CrossRef] [PubMed]

33. Janbaz, K.H.; Saeed, S.A.; Gilani, A.H. Protective effect of rutin on paracetamol and CCl4-induced hepatotoxicity in rodents. Fitoterapia 2002, 73, 557-563. [CrossRef]

34. La Casa, C.; Villegas, I.; Alarcón de la Lastra, C.; Motilva, V.; Martín Calero, M.J. Evidence for protective and antioxidant properties of rutin, a natural flavone, against ethanol induced gastric lesions. J. Ethnopharmacol. 2000, 71, 45-53. [CrossRef]

35. Wang, D.; Sun-Waterhouse, D.; Li, F.; Xin, L.; Li, D. MicroRNAs as molecular targets of quercetin and its derivatives underlying their biological effects: A preclinical strategy. Crit. Rev. Food Sci. Nutr. 2019, 59, 2189-2201. [CrossRef]

36. Nardini, M.; D'Aquino, M.; Tomassi, G.; Gentili, V.; di Felice, M.; Scaccini, C. Inhibition of human low density lipoprotein oxidation by caffeic acid and other hydroxycinnamic acid derivatives. Free Radic. Biol. Med. 1995, 19, 541-552. [CrossRef]

37. Elmas, E.P.; AyşsKaradağ, O.; Alasalvar, C. Phenolic profiles and antioxidant activity of Turkish Tombul hazelnut samples (natural, roasted, and roasted hazelnut skin). Food Chem, 2018; 244, 102-108. [CrossRef]

38. Vinayagam, R.; Jayachandran, M.; Xu, B. Antidiabetic effects of simple phenolic acids: A comprehensive review. Phytother. Res. 2016, 30, 184-199. [CrossRef]

39. Wang, S.J.; Zeng, J.; Yang, B.K.; Zhong, Y.M. Bioavailability of caffeic acid in rats and its absorption properties in the Caco-2 cell model. Pharm. Biol. 2014, 52, 1150-1157. [CrossRef]

40. Olthof, M.R.; Hollman, M.R.; Katan, M.B. Chlorogenic acid and caffeic acid are absorbed in humans. J. Nutr. 2001, 131, 66-71. [CrossRef]

41. Shahidi, F.; Alasalvar, C.; Liyana-Pathirana, C.M. Antioxidant phytochemicals in hazelnut kernel (Corylus avellana L.) and hazelnut byproducts. J. Agric. Food Chem. 2007, 55, 1212-1220. [CrossRef]

42. Ivanovic, S.; Avramovic, N.; Dojcinovic, B.; Trifunovic, S.; Novakovic, M.; Teševic, V.; Mandic, B. Chemical Composition, Total Phenols and Flavonoids Contents and Antioxidant Activity as Nutritive Potential of Roasted Hazelnut Skins (Corylus avellana L.). Foods 2020, 9, 430. [CrossRef] [PubMed]

43. Singleton, V.L.; Rossi, J.A. Colorimetry of total phenolics with phosphomolybdic-phosphotungstic acid reagents. Am. J. Enol. 1965, 16, 144-158.

44. Qin, P.; Wang, Q.; Shan, F.; Hou, Z.; Ren, G. Nutritional composition and flavonoids content of flour from different buckwheat cultivars. Int. J. Food Sci. Technol. 2010, 45, 951-958. [CrossRef]

45. Benzie, I.F.; Strain, J.J. Ferric reducing/antioxidant power assay: Direct measure of total antioxidant activity of biological fluids and modified version for simultaneous measurement of total antioxidant power and ascorbic acid concentration. Methods Enzym. 1999, 299, 15-27. [CrossRef]

46. AOAC. Official Methods of Analysis, 17th ed.; AOAC International: Gaithersburg, MD, USA, 2000. 